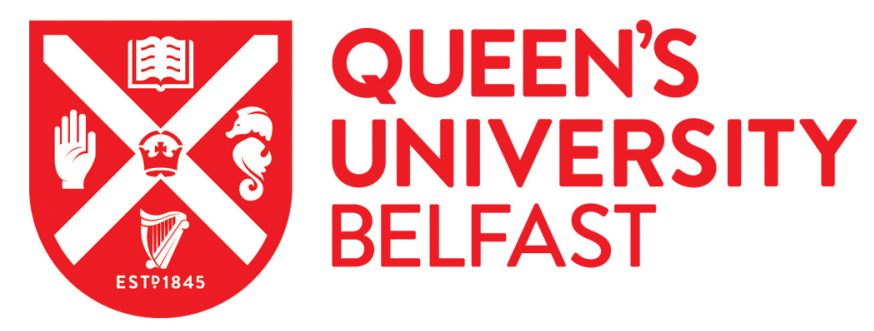

\title{
Biovolatilization of Arsenic as Arsines from Seawater
}

Savage, L., Carey, M., Williams, P. N., \& Meharg, A. A. (2018). Biovolatilization of Arsenic as Arsines from Seawater. Environmental science \& technology, 52(7), 3968. https://doi.org/10.1021/acs.est.7b06456

\author{
Published in: \\ Environmental science \& technology
}

Document Version:

Peer reviewed version

Queen's University Belfast - Research Portal:

Link to publication record in Queen's University Belfast Research Portal

Publisher rights

(C) 2018 American Chemical Society.

This work is made available online in accordance with the publisher's policies. Please refer to any applicable terms of use of the publisher.

\section{General rights}

Copyright for the publications made accessible via the Queen's University Belfast Research Portal is retained by the author(s) and / or other copyright owners and it is a condition of accessing these publications that users recognise and abide by the legal requirements associated with these rights.

Take down policy

The Research Portal is Queen's institutional repository that provides access to Queen's research output. Every effort has been made to ensure that content in the Research Portal does not infringe any person's rights, or applicable UK laws. If you discover content in the Research Portal that you believe breaches copyright or violates any law, please contact openaccess@qub.ac.uk. 
1 Biovolatilization of arsenic as arsines from seawater

2 Laurie Savage ${ }^{\dagger}$, Manus Carey ${ }^{\dagger}$, Paul N. Williams ${ }^{\dagger}$, Andrew A. Meharg ${ }^{*}{ }^{\dagger}$

3

$4{ }^{\dagger}$. Institute for Global Food Security, Queen's University Belfast, David Keir Building, Malone 5 Road, Belfast, BT9 5BN, Northern Ireland.

6

$7 \quad$ *. Corresponding author.

8

9

10

11

12

13

14 
17 Marine sources of arsenic to the atmosphere are normally dismissed as minor. Here we

18 show that arsenic can be biovolatilized from seawater, and that biovolatilzation is based on

19 organic arsenic species present in the seawater. Even though inorganic arsenic is in great excess in seawaters, it is trimethylarsine (TMA) that is the primary biovolatilized product,

21 with dimethylarsine (DMA) also observed if dimethylarsinic acid (DMAA) is spiked into

22 seawaters. With respect to budgets, $0.04 \%$ of the total arsenic in the seawater was

23 biovolatilized over a 2-week incubation period. To test the environmental significance of this

24 finding, wet deposition was analyzed for arsenic species at coastal locations, one of which

25 was the origin of the seawater. It was found that the oxidized product of TMA,

26 trimethylarsine oxide (TMAO), and to a less extent DMAA, were widely present. When

27 outputs for arsines $\left(0.9 \mathrm{nmol} / \mathrm{m}^{2} / \mathrm{d}\right)$ from seawater and inputs from wet deposition (0.3-0.5

$28 \mathrm{nmol} / \mathrm{m}^{2} / \mathrm{d}$ ) were compared, they were of the same order of magnitude. These findings

29 provide impetus to reexamining the global arsenic cycle as there is now a need to determine

30 the flux of arsines from the ocean to the atmosphere.

31

32 


\section{- INTRODUCTION}

The biogeochemical cycle of arsenic, particularly the fluxes through the atmosphere, is poorly described $(1,2)$. These fluxes are thought to be biovolatilization, salt spray entrainment, entrainment of soil dusts, and industrial emissions (1). The uncertainty regarding inputs of arsenic into the atmosphere is due to limited actual field measurements, using outdated analytical approaches, with limited arsenic speciation conducted (1). The observation that trimethylarsine oxide (TMAO) constitutes $\sim 20 \%$ of arsenic in wet deposition, from weather whose back-trajectories are marine, raised the hypothesis that TMAO in the atmosphere could be of marine origin (3). TMAO is the oxidized form of trimethylarsine (TMA), the main form of arsenic biovolatilized by fungi and bacteria (4-6). However, a previous observation that TMAO was bound to marine sampled atmospheric particulates, sampled on a remote Japanese island in the S. China Sea, was attributed to evolution of arsines from (mainland Japanese) soil (7). Trace levels of monomethylarsonic acid (MMAA), dimethylarsinic acid (DMAA) and TMAO have been detected on atmospheric particulates collected on Atlantic and Pacific cruises, at similar concentrations for each ocean, circa. $10 \mathrm{pg} / \mathrm{m}^{3}, 50-500$-fold lower than inorganic arsenic (8). There was not a clear pattern in MMAA, DMAA and TMAO concentrations, which contrasts with a later Argentinian terrestrial study that found TMAO at concentrations in particulates at $60 \mathrm{pg} / \mathrm{m}^{3}$, with DMAA 5-fold, and MMAA 10-fold, lower (9). Soils have been widely shown to produce arsines, with TMA being the dominant species produced $(5,6)$. This soil source hypothesis for TMAO in marine sampled particulates (7), though, ignored the fact that Japan, and other sampling locations $(8,9)$, are surrounded by, or are beside, oceans, and that the prevailing weather trajectories originate from the oceans. 
58 The literature on marine production of arsines is scant, though marine production of arsines

59 is predicted to be important (2). There is only one study on marine algal isolates, showing that they could biovolatilize arsenic, though speciation of these arsines was not ascertained

(4). Wet deposition studies that speciate arsenic are limited to one seaboard (3) and one continental (10) setting; with the continental low, and the seaboard one high, relatively, in TMAO. The metabolic precursors of TMA/TMAO have been found widely in seawaters, MMAA and DMAA $(11,12)$. TMAO can also be the product of arsenobetaine (AsB) degradation (13), a dominant arsenic species in marine biomass. Assessing arsenic speciation in seawater is difficult as the high salt content interferes with chromatography, and the chromatography is often not well resolved with key species co-eluting; such as for anion exchange chromatography where AsB, arsenite and TMAO can co-elute (3). Also, given that there are limited analytical standards in circulation for TMAO, it is not widely reported in the literature (3). In a recent study where multiple marine water certified reference materials (CRMs) were speciated by arsine generation, with those species cryotrapped and the cryo-trap interfaced with inductively coupled plasma - mass spectrometry (ICP-MS), TMAO was quantified at $\sim 0.2 \mathrm{nM}$ concentrations (14). As well as seawater, TMAO/TMA can emanate from soils (15), and can have a volcanic/geothermal origin (16), though the contribution of soils and geothermal sources to the wider environment is relatively low $(3,15,16)$.

To test the hypothesis of Savage et al. (3) that TMAO in wet deposition is primarily from marine origin, natural seawaters have to be shown to produce arsines, an experiment that has not been conducted, to date. In this study, we trap arsines emanating from seawater 
81 under both un-amended and DMAA amended conditions. The DMAA addition will show if

82 arsines production is methylated substrate availability inhibited, and whether any DMAA is

83 converted to TMA, to ascertain if DMMA is a precursor to biovolatilization. Furthermore, we

84 establish organic arsenic species in wet deposition at coastal locations, rather than the

85 inland sites used in previous wet deposition speciation studies $(3,10)$.

86 


\section{Generation of arsines from seawater}

89

Fresh seawater was obtained from Belfast Lough, Irish Sea, $54.644^{\circ} \mathrm{N}, 5.812^{\circ} \mathrm{W}$ (Figure 1) during September 2017. The seawater was transported directly back to the laboratory (30 minutes from sampling site) and immediately transferred into 1 L Quickfit reaction vessels fitted with a Drechsel head with a sintered glass bubbler, with the bubbler positioned below the water line. Connected to the reaction chamber inlets and outlets, were silica gel sampling tubes, dosed with silver nitrate according to Mestrot et al. (15). A personnel gas sampling pump (Pocket Pump, SKC, Dorset, UK) was then joined to the outlet tube, with air drawn into the chamber under negative pressure at a rate of $200 \mathrm{mls} / \mathrm{min}$. Eight such microcosms were set up and placed in an Memmert AtmoCONTROL incubator, set at a temperature of $20^{\circ} \mathrm{C}$, and lit with LED lights at an intensity of 8,000 lux. After 1-week the inlet and outlet tubes were replaced, and DMAA added to four of the microcosms at a dosing of $1 \mathrm{nM}$. Chemical and instrument suppliers, and analytical instruments suppliers and conditions, and are given for all analysis in Table S1. This concentration of DMAA (1nM) is near the upper limit of what we recorded in Irish wet deposition as outlined in this study. The microcosms were then incubated for a further week, with traps removed and analyzed.

Arsenic species trapped on the silver nitrate impregnated silver gel were eluted with $\sim 5 \mathrm{ml}$ boiling water, volume accurately measured, for subsequent chromatographic quantification of species (15). Arsenic species in the seawater were determined in triplicate following 10fold dilution and oxidation of any arsenite to arsenate with $0.3 \%$ final concentration of $\mathrm{H}_{2} \mathrm{O}_{2}$, to move arsenite away from the co-eluting species, AsB and MMAA. For speciation, a 
Thermo Scientific IC5000 Ion Chromatography system interfaced with a Thermo ICAP-Q ICP-

111 MS was used. Chromatography utilized a 2x250mm Thermo Scientific AS7 anion-exchange

112 column with a $2 \times 50 \mathrm{~mm}$ AG7 guard column and ammonium carbonate over a linear gradient

113 from $20 \mathrm{nM}$ to $200 \mathrm{nM}$ was the mobile phase. Purchased standards, suppliers detailed in

114 Table S1, of arsenobetaine, inorganic arsenic, MMAA, DMAA, and TMAO were run to

115 ascertain retention times, and for quantification of those species. Total arsenic was

116 determined in triplicate seawater samples following Millipore membrane (0.45 micron)

117 filtering on 10 -fold diluted samples.

119 For total arsenic determination, the Thermo Scientific ICAP-Q ICP-MS was used in helium

120 collision cell mode to quantify arsenic against authentic samples with rhodium used as an external standard, spiked to give a $10 \mu \mathrm{g} / \mathrm{l}$ concentration. For all analytical methods, blanks were prepared from $>18.2 \mathrm{M} \Omega . \mathrm{cm}\left(\right.$ at $25^{\circ} \mathrm{C}$ ) water in the same manner as the samples and included with each instrument batch. Limit of Detection (LOD) was calculated as average concentration of the blank +3 times standard deviation of a species mix dilution series.

\section{Arsenic speciation in wet deposition}

127 Wet deposition was collected during July and August 2015 at two sampling locations, the Belfast location used for seawater collection, and an Atlantic coastal location, Caherdaniel, Co. Kerry, Republic of Ireland, $51.769^{\circ} \mathrm{N}, 10.099^{\circ} \mathrm{W}$. Bulk deposition was collected in $56 \mathrm{~mm}$ mouth diameter, pre-weighed, polypropylene $30 \mathrm{ml}$ sampling tubes, suspended $1.5 \mathrm{~m}$ off the ground to avoid splash back, for $24-\mathrm{h}$ and immediately frozen on collection. Volume of wet deposition collected was measured gravimetrically, and then converted to a deposition volume on a surface area basis. Defrosted samples were 0.45 micron filtered, $\mathrm{H}_{2} \mathrm{O}_{2}$ added 
134 to $1 \%$, and arsenic species quantified by IC-ICP-MS, as detailed in Savage et al. (3). The 72-h 135 air trajectories for each location at each date was modelled by Hysplit (17) as per Savage et 136 al. (3). 


\section{Biovolatilization of arsenic from seawater}

141 The total arsenic present in the fresh seawater was $26.0 \pm 0.6 \mathrm{nM}$. Speciation was quantified

142 using anion-exchange in a 1/10 seawater dilution. The sum of species was $18.5 \mathrm{nM}$, with 7.5

$143 \mathrm{nM}$ difference in total arsenic being due to arsenic species retained on column or peak

144 broadened below LoD due to salinity. Speciated compounds were inorganic arsenic at $16.5 \pm$

$1450.7 \mathrm{nM}$, and DMAA at $1.4 \pm 0.7 \mathrm{nM}$. A peak was observed where TMAO/AsB eluted at $0.59 \pm$

$1461.1 \mathrm{nM}$, but was not apparent on the cation exchange chromatographic runs. TMAO has

147 severe peak broadening on the cationic column in the presence of seawater and is not

148 quantifiable. AsB is not peak broadened on the cationic column, suggesting the unidentified

149 peak is TMAO. The AsB/TMAO peak merged into the DMAA peak at lower sea water

150 dilutions ( $\mathrm{X} 1$ and $\mathrm{X} 2)$ and was below LoD (0.08 nM) at higher dilutions (X100). No MMAA

151 above LoD was present in any of the dilutions.

152

153 Only 3 arsenic species, TMAO, DMAA and inorganic arsenic were present on seawater

154 microcosm outlet chemo-traps; while only two were detectable on inlets, DMAA and

155 inorganic arsenic (Figure 2). The $1 / 2$ Limit of Detection (LoD) for TMAO was calculated at 64

$156 \mathrm{pM}$ in solution extract; the trap was diluted to $\sim 5 \mathrm{ml}$. The inlet concentration was subtracted

157 from the outlet concentration and the data expressed on the quantity of arsines

158 biovolatilized from $1 \mathrm{~L}$ of seawater over one week (Figure 3). During the first week of

159 sampling, $\mathrm{AsH}_{3}$ was produced/trapped at a rate of $2.9 \mathrm{pmol} / \mathrm{L} / \mathrm{wk}$, which was significant

160 based on one-way anova analysis at $\mathrm{P}=0.05$, but fluxes were negligible for week 2 ,

161 regardless of DMAA treatment. DMA biovolatilization was negligible for weeks 1 and 2

162 without DMAA addition, but production was $15.8 \mathrm{pmol} / \mathrm{L} / \mathrm{wk}$ for the DMAA treatment, 
significant at $\mathrm{P}<0.0001$. TMA was produced at a rate of $3.0 \mathrm{pmol} / \mathrm{L} / \mathrm{wk}$ for the first week incubation, and increased to $8.3 \mathrm{pmol} / \mathrm{L} / \mathrm{wk}$ in the second week without DMAA addition, and $14.7 \mathrm{pmol} / \mathrm{L} / \mathrm{wk}$ with DMAA addition, $\mathrm{P}=0.013$ for the one-way anova for the 3-way comparisons, with the only pairwise comparison that was significant being week 1 versus week 2 with the DMA amendment $(P=0.0124)$. The sum of $(\Sigma)$ arsenic species increased from 5.1 to $9.0 \mathrm{pmol} / \mathrm{L} / \mathrm{wk}$ in the absence of additional DMAA in week 2, and with DMAA this figure was $32.2 \mathrm{pmol} / \mathrm{L} / \mathrm{wk}$, with one-way-anova being highly significant $(P=0.0008)$. The $\sum$ arsenic species biovolatilized was $0.01 \%$ of total seawater arsenic for week one and $0.03 \%$ for week two without DMAA. The additional $\sum$ arsenic species biovolatilized in the week 2 DMAA treated minus the non-DMAA treated microcosms, expressed as a percentage of the DMAA added, was 23.5\%.

\section{Arsenic speciation in wet deposition}

Two sampling sites were used to study arsenic inputs in wet deposition (Figure 1). The Kerry site, in the S.W. of Ireland on the Atlantic coast, is one of the most remote and unpolluted regions of Europe, dominated with Atlantic originating weather trajectories delivering wet deposition (Figure 1). Belfast is situated on the Irish Sea, and while still remote in a European context, has a history of industrialization and is closer to Europe, but still receives predominantly wet deposition from Atlantic originating trajectories (Figure 1). The Kerry location had higher concentrations of TMAO and DMAA throughout, and at lower depositional volumes, also higher inorganic arsenic concentrations (Figure 4 and Table 1). TMAO and inorganic arsenic were routinely above the LoD (LoDs given in Table 1) at deposition volumes below $5 \mathrm{~L} / \mathrm{m} 2 / \mathrm{d}$, while DMAA had only one sample above LoD for Belfast, but was above LoD for half the Kerry samples. DMAA was too low to observe any 
clear washout, i.e. the relationship between arsenic species concentration and depositional 188 volume, but for TMAO at both sites, and also for inorganic arsenic at the Kerry site, this was 189 clear and steep, fitting exponential decay functions. Inorganic arsenic was more erratic, and 190 could be high at higher depositional volumes, for Belfast, with no clear exponential decay 191 relationship for washout.

192

193 Considering depositional inputs of the 3-arsenic species (Table 1). Inorganic arsenic inputs 194 were 2.6-fold higher for Belfast, though not significantly so ( $P>0.05)$. DMAA was similar for 195 both sites, but this is an estimate given that the Belfast sites were mainly below LoD, and $1 / 2$ 196 LoD was used in this calculation. TMAO was significantly $(P<0.0001)$ higher, 1.6-fold, in Kerry 197 compared to Belfast. Comparing these wet depositional inputs with seawater 198 biovolatilization for TMA (Figure 3), assuming that biovolatilization is occurring to a depth of $1991 \mathrm{M}$, and averaging TMA production for week 1 and 2 , then $1 \mathrm{~m}^{2}$ of seawater can produce $2000.86 \mathrm{nmol} / \mathrm{m}^{2} / \mathrm{d}$. Wet depositional inputs of TMAO was at a rate of 0.31 and 0.50 $201 \mathrm{nmol} / \mathrm{m}^{2} / \mathrm{d}$ for Belfast and Kerry respectively, i.e. just lower than potential seawater TMAO 202 production. 
204 The results presented here show that arsines, particularly, TMA, can be biovolatilized from

205 seawaters at rates commensurate with inputs from wet deposition, suggesting very close

206 linking between the two, and explaining observations that TMAO deposition occurs when

207 weather trajectories are of marine origin (3). It also calls into question that TMAO observed

208 in marine particulates are of terrestrial origin, as has previously been hypothesized (7). The

209 fact that higher concentrations in wet deposition, and higher depositional rates of TMAO

210 were observed in a remote S.W. Irish location, as compared to an industrialized N.E. Irish

211 location, points to a natural origin of this TMA/TMAO for both sites, given that Belfast is also on an Irish Sea coastal location. That S.W. Irish rainwater concentrations of TMAO were higher could be due to both Kerry sitting on a larger water body, the Atlantic, and due to the fact that Belfast weather trajectories, as for Kerry, are predominantly westerly, but that they also have to travel over the Irish landmass, for most trajectory pathways. The concentrations of $\Sigma$ arsenic species recorded here relate well to previous $20^{\text {th }}$ century observations for total arsenic for Bermuda, Eastern Atlantic (18) and Western Pacific locations (19), and to our own Indian Ocean measurements (3). These illustrate the ubiquity of arsenic in maritime derived wet deposition.

TMAO is rapidly washed out of the atmosphere, and thus longer weather paths over land would decrease atmospheric burdens of TMAO when precipitation is occurring. This steep washout curve, and the ubiquity of TMAO in wet deposition samples, had been shown in our previous Indian Ocean investigations (3). For the Indian Ocean (3), TMAO inputs were lower in winter as compared to summer, even though weather trajectories come from the same locations. As organic arsenic species in the water column are seasonal in the Indian 
Ocean, with DMA being higher during summer months (13), production and availability of organo-arsenic species in the water column may be key to understanding seawater biovolatilization of arsenic. Atlantic algal productivity has also been linked to total arsenic deposition at a west Britain location, when air trajectories were so aligned (20).

Previous studies on arsenic speciation in Atlantic waters find that DMAA concentrations of 0.1-0.3 nM are typical, rapidly decreasing with depth $(>50 \mathrm{~m})$ to below LoD. $(12,21,22)$.

Higher DMAA concentrations, similar to ours at $\sim 1 \mathrm{nM}$, were reported from the continental shelf off the American east coast (12) and multiple European west coasts continental shelf locations (23). This suggests that methylation of arsenic is more active in a shelf setting. In deeper ocean surface-waters, the lower concentration of DMAA does not appear to be due to limitation in total or inorganic arsenic, a metabolic precursor (4), as inorganic arsenic is typically $10-20 \mathrm{nM}$ for both open ocean and coastal shelf waters $(12,21-23)$. MMAA is less commonly reported. It is mainly below LoD for a French coast study (23), as for our Irish Sea location here. It is below LoD in other Atlantic studies $(21,22)$, and averaging $0.13 \mathrm{nM}$ in another (12). It should be noted that only direct analysis of arsenic speciation was made using the French study (23), while the other Atlantic studies used indirect assessment of arsenic species (photo-ionization detection) $(12,21,22)$. Using a highly sensitive and accurate speciation approach, on seawater certified reference materials, Matousek et al. (14) measured TMAO in coastal and off-shore waters at concentrations ranging from 0.16-0.3 $\mathrm{nM}$, higher than MMAA (0.03-0.12nM), whereas DMAA ranged from 0.53-1.64 nM, and inorganic arsenic was $\sim 14$ nM. Thus, when specifically looked for, i.e. using appropriate analytical methodologies, TMAO appears to be present at lower concentrations than DMAA, but higher than MMAA (14). The fact that TMAO is always higher than DMAA in wet 
deposition, with DMAA often below LoD, yet DMAA concentrations are higher in seawaters, argues for TMAO coming from a biovolatilization route rather than salt spray, as has been previously postulated to be the source of arsenic in wet deposition (1). Also, MMAA and TMAO appear to have similar concentrations in seawaters (14), yet MMAA is never recorded in wet deposition, probably as it is below LoD, not just absent. MMAA $<$ LoD, again, argues for TMAO in wet deposition being from a biovolatilization, as opposed to a salt spray, source. Low TMAO concentrations in the water column may be expected if TMAO is rapidly converted to TMA and lost from the water column.

The only previous study on biovolatilization from a marine media was a micro-algal pure culture study (4). Arsenate was added at $20,000 \mathrm{nM}$ concentration to incubating Ostreococcus tauri under optimal culture conditions, and $0.01 \%$ of this arsenic was converted to arsines. Even though our total arsenic concentrations in seawater were a 1000 times lower, and that any biovolatilizing microbial community was present at natural densities, we found similar conversion of dissolved seawater arsenic to arsines, $0.04 \%$ over 2-week incubation. While Zhang et al. (4) did not speciate trapped arsines, they did speciate the incubating medium where they found $2.4 \%$ of added inorganic arsenic converted to DMAA, but no MMAA was detected. TMAO and AsB were not looked for, or, at least, too low to report. Given that TMAO and AsB can co-elute with other species (3), and seawater interferes with TMAO detection, TMAO (if present) may not have been observed under the chromatographic conditions used. In a study on freshwater photosynthetic cyanobacteria where the arsenic methylating protein ArsM was isolated, it was shown to convert inorganic arsenic to arsines in vitro, with $2 \%$ of arsenic in the incubating medium converted to TMA, alone (24). TMAO, DMAA and MMMA were all detected in culture solution after addition of 
inorganic arsenic, in both purified ArsM studies and where the ArsM gene was cloned into

Escherichia coli. When DMAA was added directly to our microcosms we saw a $23 \%$ conversion to DMA. DMAA addition enhanced the production of TMA by $77 \%$, showing methylation and reduction of DMAA to biovolatilized TMA. As DMAA was detected in seawaters at circa. the same levels as the amendment, it is likely that the exogenously added DMAA was rapidly metabolized, and the natural DMAA in the seawater was within cells and lysed on preparation for analysis. This is consistent with findings on algae where the bulk of the arsenic in microcosms is within the cells $(4,24)$. Another observation of our study was that TMAO production from both non-amended seawater increased during the second week, suggesting enhanced arsenic species turnover during week 2 . The pathways and regulation of arsenic methylation in natural seawaters needs further investigation. It is becoming apparent that seawater contribution to the global arsenic cycle has been underestimated, and marine biovolatilization as a source ignored by all but a handful of studies $(3,4)$. Matschullat $(1)$ estimated that $27 \mathrm{t}$ of arsenic in the global atmosphere was derived from salt-spray. Although our measurements are limited in geography and time, they are the only measurements of TMA output and TMAO input to be conducted to date. There is now a need to estimate the contribution of marine produced arsines to arsenics global arsenic cycle.

Wet deposition, reported here, and in Savage et al. (3), and measured seawater TMAO concentrations (14), are in the same range sub-nM. It also has to be considered that wet deposition direct to seawaters, or runoff from terrestrial wet deposition, will also be a source of TMAO to seawaters, and there might be tight recycling of TMAO depositional inputs to TMA outputs, which are then oxidized in the atmosphere to TMAO, before re- 
deposition. However, demethylation of TMAO also has to be considered as a potential fate

300 of TMAO in the water column as well (13). TMAO can also be derived from AsB degradation

301 (13), and the role of this pathway also remains to be investigated in the context of

302 biomethylation.

303

304

- ASSOCIATED CONTENT

305 The Supporting Information contains 1 table pertaining to analytical reagents and analytical 306 instrument parameters.

307

308

- REFERENCES

309

310

1. Matschullat, J. Arsenic in the geosphere. Sci. Total Environ. 2000, 249, 297-312.

311

2. Mestrot, A.; Planer-Friedrich, B; Feldmann, J. Biovolatilisation: a poorly studied pathway of the arsenic biogeochemical cycle. Environ. Sci. Processes Impacts 2012, $15,1639$.

3. Savage, L.; Carey, M.; Hossain, M.; Islam, M.R.; de Silva, P.M.C.S.; Williams, P.N.; Meharg, A.A. Elevated trimethylarsine oxide and inorganic arsenic in northern hemisphere summer monsoonal wet deposition. Environ. Sci. Technol. 2017, in press DOI: $10.1021 /$ acs.est.7b04356

4. Zhang, S. -Y.; Sun, G. -X.; Yin, X. -X.; Rensing, C.; Zhu, Y. -G. Biomethylation and volatilization of arsenic by the marine microalgae Ostreococcus tauri. Chemosph. 2013, 93, 47-53. 
5. Zhu, Y.G.; Xue, X.M; Kappler, A.; Rosen, B.; Meharg, A.A. Linking genes to microbial biogeochemical cycling: lessons from arsenic. Environ. Sci. Technol. 2017, 51, 73267339.

6. Zhao, F.J.; Zhu, Y.G.; Meharg, A.A. Methylated arsenic species in rice: geographical variation, origin and uptake mechanisms. Environ. Sci. Technol. 2013, 47, 3957-3966.

7. Mukai, H.; Ambe, Y.; Muku, T., Takeshita, K. Seasonal variation of methylarsenic compounds in airborne particulate matter. Nature 1986, 324, 239-241.

8. Nakamura, M.; Matsuzono, Y.; Tanaka, S.; Hashimito, Y. Chemical form of arsenic Organomet. Chem., 4, 1990, 223-230.

9. Jakob, R.; Roth, A.; Haas, K.; Krupp, E. M.; Raab, A.; Smichowski, P.; Gomez, D.; Feldmann, J. Atmospheric stability of arsines and the determination of their oxidative products in atmospheric aerosols $\left(\mathrm{PM}_{10}\right)$ : evidence of the widespread phenomena of biovolatilization of arsenic. J. Environ. Monit. 2010, 12, 409-416.

10. Huang, J. -H.; Matzner, E. Biogeochemistry of organic and inorganic arsenic species in a forested catchment in Germany. Environ. Sci. Technol.2007, 41, 1564-1569.

11. Tanaka, S.; Santosa, S. J.; The concentration distribution and chemical form of arsenic compounds in sea water. In: Biogeochical Processes and Ocean Flux in the Western Pacific. Eds Sakai, H.; Nozaki, Y. pp. 159-170, Terra Scientific Pub. Comp., Tokyo, 1995.

12. Wurl, O.; Shelley, R. U.; Landing, W. M.; Cutter, G. A. Biogeochemistry of dissolved arsenic in the temperate to tropical North Atlantic Ocean. Deep-Sea Res. // 2015, $116,240-250$. 
13. Hanaoka, K.; Nakamura, O.; Ohno, H.; Tagawa, S.; Kaise, T. Degradation of arsenobetaine to inorganic arsenic by bacteria in seawater. Hydrobio. 1995, 316, 7580.

14. Matoušek, T.; Currier, J. M.; Trojánková, N.; Saunders, R. J.; Ishida, M. C.; GonzálezHorta, C.; Musil, S.; Mester, Z.; Stýblo, M.; Dědina, J. Selective hydride generationcryotrapping-ICP-MS for arsenic speciation analysis at pictogram levels: analysis of river and sea water reference materials and human bladder epithelial cells. J. Anal. At. Spectrom. 2013, 28, 1456-1465.

15. Mestrot, A.; Feldmann, J.; Krupp, E. M; Hossain, M. S.; Roman-Ross, G.; Meharg, A. A. Field fluxes and speciation of arsines emanating from soils. Environ. Sci. Technol.

16. Arndt, J.; Ilge, G.; Planer-Friedrich, B. Evaluation of techniques for sampling volatile arsenic on volcanoes. J. Volcan. Geotherm. Res. 2017, 331, 16-25.

17. Draxler, R. R.; Hess, G. D. An overview of the HYSPLIT_4 modeling system of trajectories, dispersion, and deposition. Aust. Meteor. Mag. 1998, 47, 295-308.

18. Cutter, G. A. Metalloids in wet deposition on Bermuda: concentrations, sources, and fluxes. J. Geophys. Res.1993, 98, 16777-16786.

19. Andreae, M. O. Arsenic in rain and the atmospheric mass balance of arsenic. J. Geophys. Res.1980, 85, 4512-4518.

20. Blazina, T.; Läderach, A.; Jones, G. D.; Sodemann, H.; Wernli, H.; Kirchner, J. W.; Winkel, H. E. Marine primary productivity as a potential indirect source of selenium 108-118. 
21. Cutter, G.A.; Cutter, L.S.; Featherstone, A.M; Lohrenz, S.E. Antimony and arsenic biogeochemistry in the western Atlantic Ocean. Deep-Sea Res. II. 2001, 48, 28952915.

22. Cutter, G.A.; Cutter, L.S. Metalloids in the high latitude North Atlanic Ocean: internal cycling. Mar. Chem. 1998, 61, 25-36.

23. Michel, P.; Boutier, B.; Herbland, A.; Averty, B.; Artigas, L.F.; Auger, D. Chartier, E. Behaviour of arsenic on the continental shelf of the Girode estuary: role of phytoplankton in vertical fluxes during spring blood conditions. Oceanolog. Acta $1998,21,325-333$.

24. Yin, X.X.; Chen, J.; Qin, J.; Sun, G.X.; Rosen, B.P.; Zhu, Y.G. Biotransformation and volatilization of arsenic by three photosynthetic cyanobacteria. Plant Physiol. 2011, 156, 1631-1638. 
383 Table 1. Concentration and rates of deposition in wet precipitation for the Belfast and Kerry 384 sampling sites. The LoDs for arsenic species were $0.12,0.13$ and $0.288 \mathrm{nM}$ for DMAA, TMAO 385 and inorganic arsenic, respectively.

\begin{tabular}{cccc}
\multicolumn{2}{c}{ concentration (nM) } & \multicolumn{2}{c}{ deposition $(\mathrm{nmol} / \mathrm{m} 2 / \mathrm{d})$} \\
$\mathrm{n}$ inorg. As DMAA TMAO inorg. As DMAA TMAO
\end{tabular}

Belfast

$\begin{array}{clllllll}\text { mean } & 32 & 0.64 & 0.05 & 0.15 & 2.32 & 0.19 & 0.31 \\ \text { S.E. } & & 0.20 & 0.01 & 0.03 & 0.78 & 0.03 & 0.04\end{array}$

Kerry

$\begin{array}{clllllll}\text { mean } & 8 & 1.14 & 0.26 & 0.58 & 0.89 & 0.20 & 0.50 \\ \text { S.E. } & & 0.34 & 0.11 & 0.15 & 0.11 & 0.04 & 0.11\end{array}$


Figure 1. Geographic location of the two sampling sites, Belfast and Kerry, used in this study,

391 along with the weather 72-h back trajectory origins modelled by HySplit. For the back

392 trajectories, black is for Belfast, red is for Kerry. The map image was created in the Mac

393 application MagicMaps.

394

395

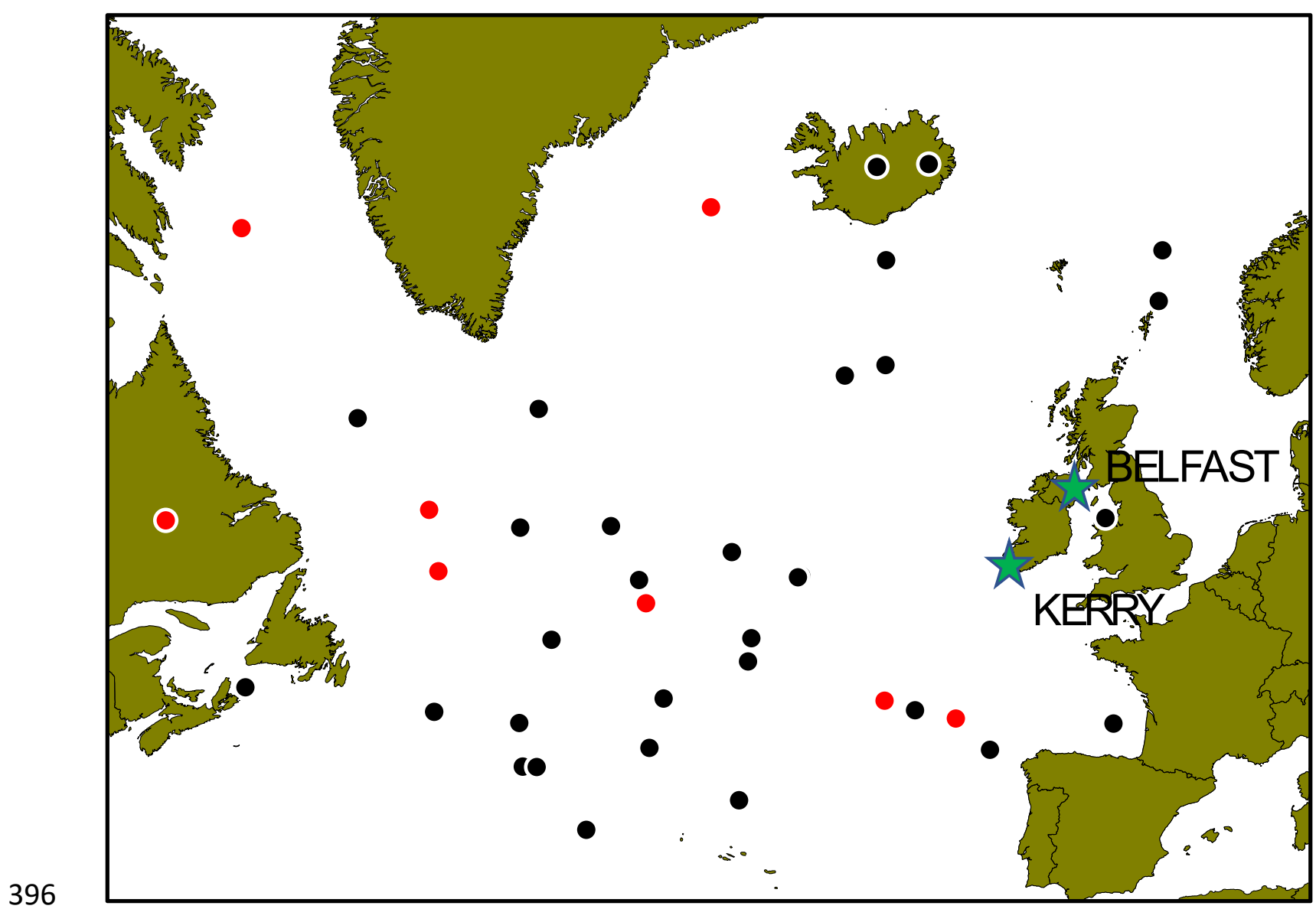

397

398

399

400

401 
Figure 2. IC-ICP-MS chromatograms for arsenic species chemo-trapped on silver nitrate from 403 incubated seawater. Chromatograms are shown in week 1 (upper) and week (2) pairs for 404 each microcosm. All 8 microcosms were untreated for week 1, and for week 2 half were left 405 untreated (left-hand column) and half treated with a final concentration of $1 \mathrm{nM} \mathrm{DMA}$. The 406 red shaded chromatographic trace is for the inlet trap; the black line trace is for the outlet 407 trap.

408
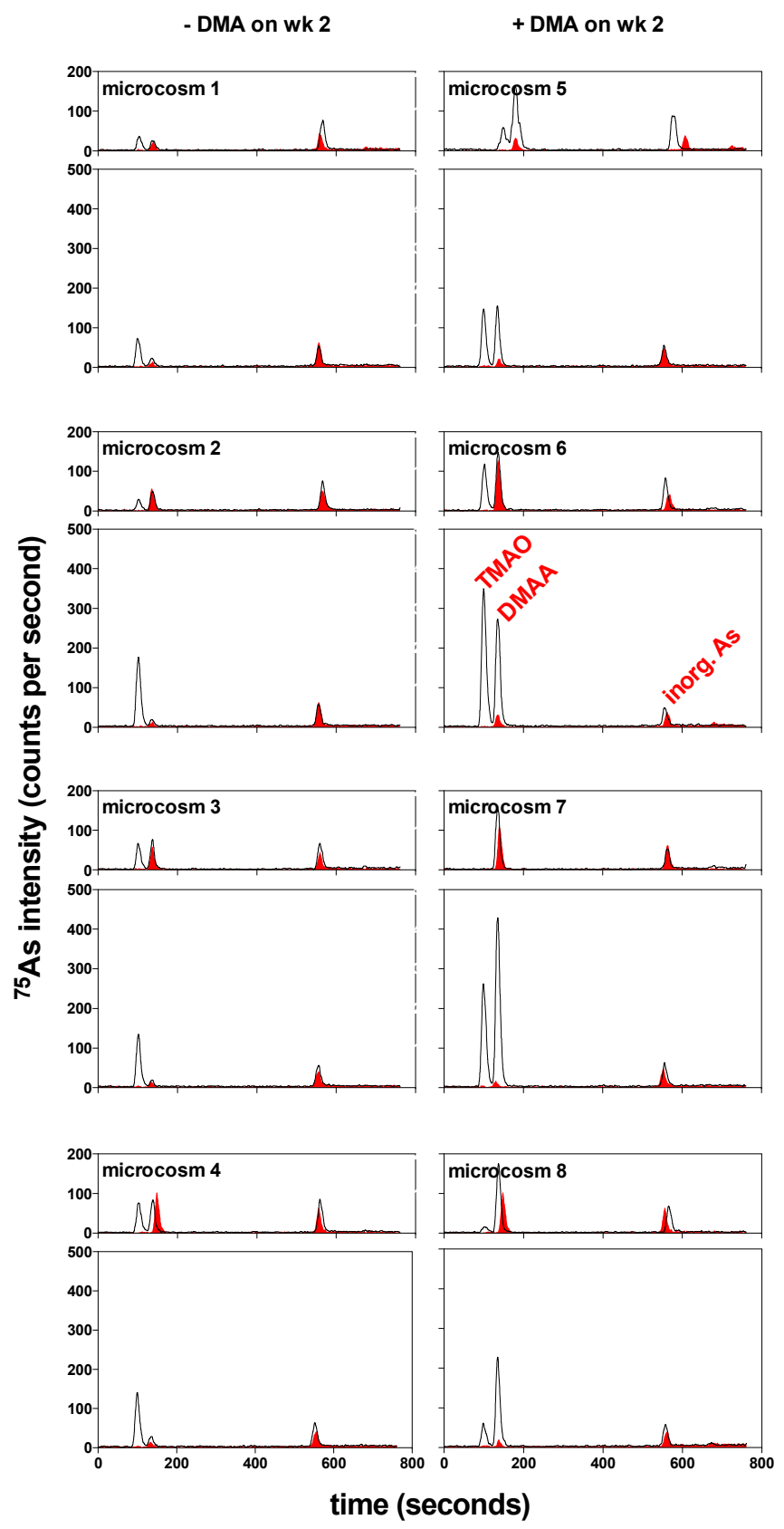
410 Figure 3. Production rate of arsines from seawater, calculated from subtracting the inlet

411 silver nitrate traps from the outlet trap quantified chromatograms presented in Figure 2.

412 Graphs show each individual microcosm by week and treatment. The horizontal red line is

413 the mean, the red vertical is the standard error of the mean.

414
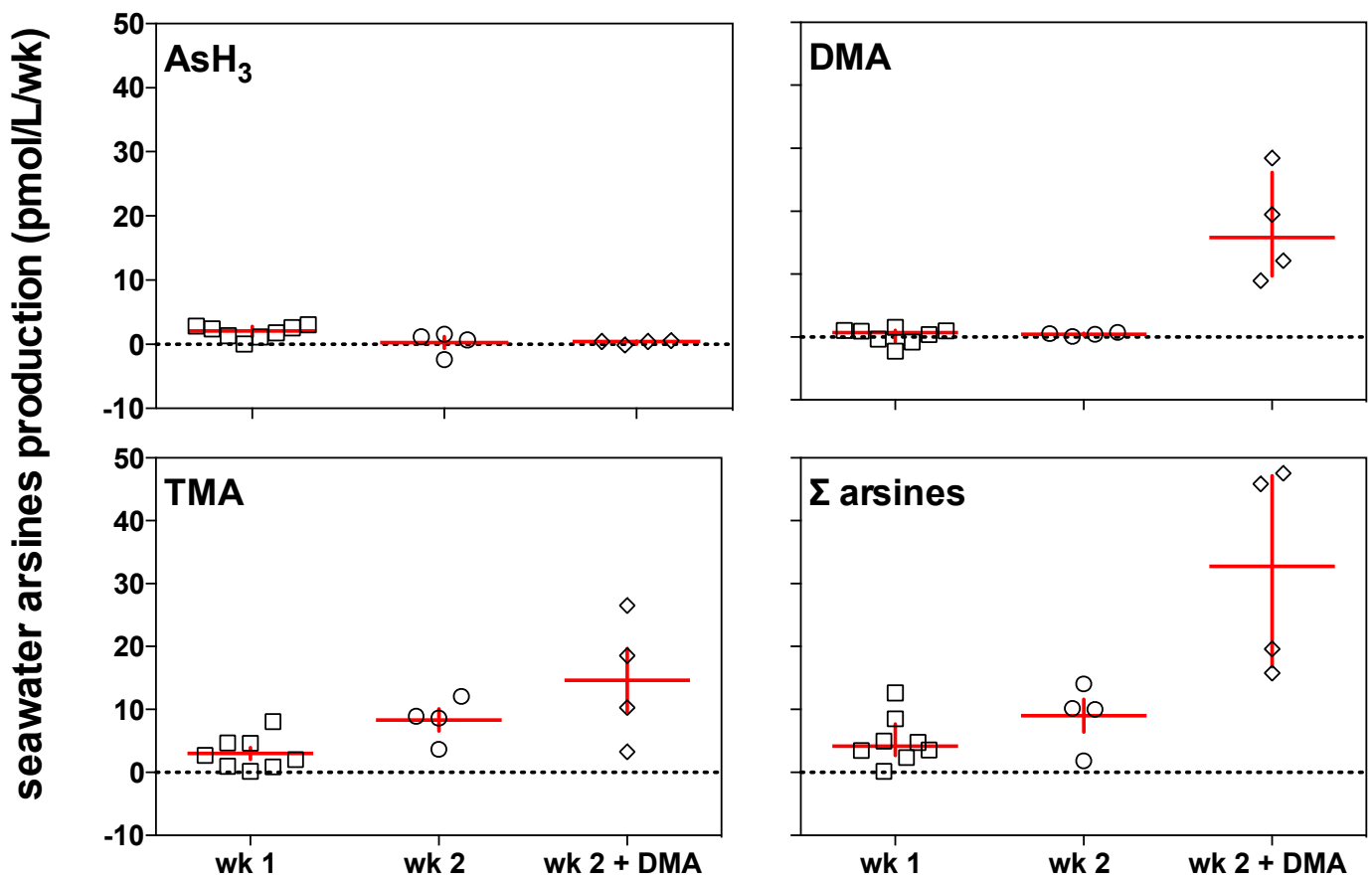

415

416

417

418

419

420

421

422

423

424 
Figure 4. Concentrations of TMA, DMA and inorganic arsenic in wet deposition collected at

426 the Belfast (black asterisk and line) and Kerry (red circle and dashed line). The lines are

427 modeled single exponential decay functions for all data except for the inorganic arsenic at

428 the Kerry site where a double exponential decay function gave a better fit. The insert in the

429 "inorganic arsenic" panel shows a sample Kerry wet deposition chromatogram with DMAA,

430 TMAO and inorganic arsenic eluting.

431
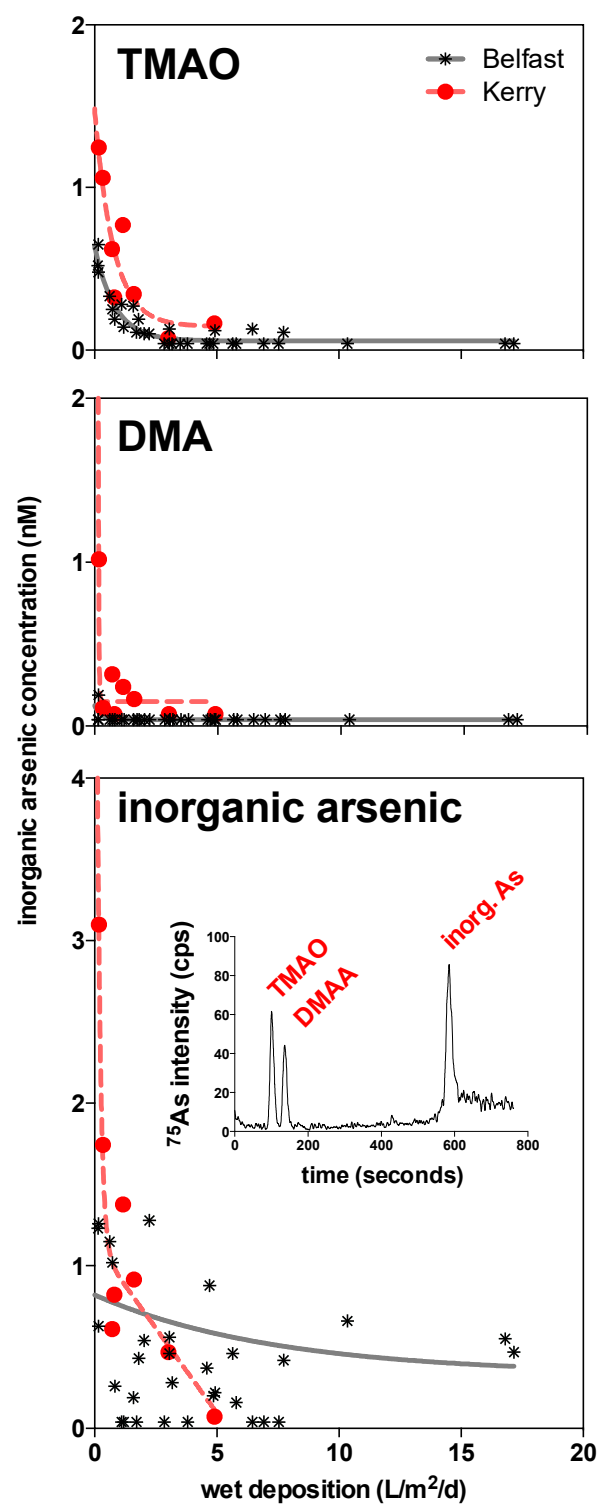

432 